\title{
Invisible Hours: Social Service Work and Unpaid Labour
}

\author{
Ley D. Fraser \\ University of Northern British Columbia, Prince George, Canada \\ Email: bfraser@unbc.ca
}

Received 28 February 2016; accepted 13 March 2016; published 17 March 2016

Copyright (C) 2016 by author and OALib.

This work is licensed under the Creative Commons Attribution International License (CC BY). http://creativecommons.org/licenses/by/4.0/

(c) (i) Open Access

\section{Abstract}

This article was based on a larger study examining emotional stress in social service workers at the intersection of professional expectations and the "emotional labour" that accompanies day-today work. Social service workers are defined for this study as individuals who are employed in a position where they provide support for individual clients' mental, emotional and social welfare over an extended period of time (this definition intentionally excluded occupations such that offer primarily medical care, which are outside the scope of the study). The results of the survey showed social work as a profession filled with mature workers whose commitment and passion for their job is tempered by the intrusive emotional labour that can claim their off hours. In addition, the findings showed that unpaid overtime is normalized in the field and workers may feel expected to give their job more than just the hours they are paid for. These findings offer some considerations for why social work experiences a high turnover rate despite the dedication and commitment of the workers.

\section{Keywords}

Emotional Labour, Overtime, Burnout, Social Services, Social Work, Turnover

Subject Areas: Demography, Psychology, Sociology

\section{Introduction}

The goals of the study were to examine the expectations of professionalism and emotional labour placed on social service workers by their employers and self-perception of these expectations as congruent or contradictory, as well as the amount of emotional labour social services workers feel compelled to offer once a caring relationship has been established with a client and whether this exceeds the hours of work for which the worker is compensated. An additional question measured whether workers were aware of any resources offered by their employer to alleviate mental and emotional distress. 
For the purposes of the study social service workers were defined as individuals who are employed for extended periods of time in providing support for individual clients' mental, emotional and social welfare. This definition was designed to encompass such occupations as group home workers, child welfare agents, and assisted living providers. The commonality that these positions share is an expectation of emotional labour, as the worker strives to create a caring relationship with the client and help the client to improve their mental, emotional and social conditions while dealing with the tension their role as a "professional" may create in the informal and relational aspects of that role [1]. Hereafter, all of the employment that fits these standards will be referred to as "social service work", and the individuals as "workers".

\section{Literature Review}

\subsection{Emotional Labour in Social Service Work}

Emotional labour is defined [2] as the "management of client emotions and workers' own emotions in the process of working with clients and delivering care under conditions of scarcity and contraction" (p. 359). This can extend to a variety of tasks ranging from dealing with clients' distress over personal issues to managing job commitments when they run over the working hours; all these emotional labours are considered an implicit part of a social workers' job though they are unseen and uncompensated [3]. Because it cannot be measured and quantified, it is unclear exactly what toll emotional labour takes on the lives of social service worker both inside and outside of their work hours, and fair compensation for emotional labour as part of social service work remains unstudied.

\subsection{Professionalism in Social Service Work}

Social service work has been subject to increasing professionalism where the relationship-building considered essential to the work is sidelined in favor of paperwork, politics and financial considerations [4]. Because there is pressure in social service work to behave in a correct, objective and non-judgmental manner workers look for "reliable and legitimate procedures and guidance" (p. 11) to be sure their behaviour is meeting that standard, and often find that guidelines fall short of offering adaptable and appropriate guidelines for the emotional labour inherent in client relationships.

This subjective analysis of professional guidelines is also influenced by the emotional labour that is considered an integral part of the job but by nature does not lend itself to standardized rules. Workers, for example, are cautioned to avoid blurring the line between the professional relationship and the more informal one of a friend or confidant [5], despite the fact that emotional labour, once required of a worker, is unlikely to adhere itself to the guidelines of an externally imposed role.

\subsection{The Risk of Burnout in Social Service Work}

Burnout [6] is defined as "emotional exhaustion, depersonalization, and a lack of a sense of personal accomplishment” (p. 272). Burnout has been identified as a major concern in the human services industry as it has been linked to numerous physical and psychological symptoms, as well as high rates of absenteeism and turnover. This makes burnout the number one concern for the human services industry, as any efforts put into training are wasted if the workers are unable to stay in the field.

A secondary factor that may contribute to burnout for social service work is gender: the majority of social service workers are female. In a 2005 study which measured subjective reports of emotional exhaustion [7], especially in situations where the individual had very little control over the outcomes, women reported significantly higher levels of emotional exhaustion than men did. In social service work it is common to encounter circumstances where the worker has limited control, due to a variety of factors including the professional expectations placed on the worker [8].

\section{Methodology}

The survey (Appendix A) was available from December $1^{\text {st }} 2014$ to February $10^{\text {th }} 2015$ on the University of Northern British Columbia (UNBC) online survey platform, the link to which was sent out by email to participating organizations. The UNBC survey platform is hosted at surveys.unbc.ca and the survey software that was used can be found at www.limesurvey.org. Sixteen social service agencies (Table 1) were recruited via 
Table 1. Organizations contacted by the researcher about passing the survey to members/employees.

\begin{tabular}{|c|c|c|}
\hline Name of organization & Method of contact & Response received $^{*}(\mathrm{Y} / \mathrm{N})$ \\
\hline BC Association of Social Workers & Facebook Post & N/A \\
\hline Eagle Nest Community and Aboriginal Services (ENCAAS) & Email & $\mathrm{N}$ \\
\hline Eagle Ed. (Education Page of ENCAAS) & Facebook Post & N/A \\
\hline Phoenix Transition House & Phone, Email & $\mathrm{Y}$ \\
\hline Prince George Native Friendship Centre (PGNFC) & Phone, Email & $\mathrm{Y}$ \\
\hline Northern Women's Centre & Phone, Email & $\mathrm{Y}$ \\
\hline College of New Caledonia (Social Service Workers' Program) & Phone, Email & $\mathrm{Y}$ \\
\hline Reconnect Youth Services & Phone, Email & $\mathrm{Y}$ \\
\hline Intersect Youth and Family Services Society & Phone, Email & $\mathrm{Y}$ \\
\hline Northern Social Work Student Association (Facebook Group) & Facebook Post & N/A \\
\hline BC’s Community Social Services Workers (Facebook Group) & Facebook Post & N/A \\
\hline $\begin{array}{c}\text { Youth Around Prince (YAP) } \\
\text { (Closed Facebook group for YAP Staff \& Affiliates) }\end{array}$ & Facebook Post & N/A \\
\hline $\begin{array}{l}\text { BC Association of Social Workers, } \\
\text { Northern Branch (Facebook Group) }\end{array}$ & Facebook Post & N/A \\
\hline social advocacy in Kamloops [sic] (Facebook Group) & Facebook Post & N/A \\
\hline Community Social Services Employers’ Association of BC & Facebook Post & N/A \\
\hline UNBC School of Social Work (Graduate and Undergraduate) & Email & $\mathrm{Y}$ \\
\hline
\end{tabular}

*While the survey link was included in all emails and posts (and could ostensibly have been passed on by anyone who received it) only organizations who replied that they would forward it on to their members/employees are listed in the response column.

publically available listings and asked to refer other organizations, which employed social service workers as defined by the survey criteria. Organizations whose members fit the survey demographic (such as the British Columbia Association of Social Workers) were also asked to forward the survey link to their members (Table 1). The survey did not ask or record which organization referred respondents, in order to respect their anonymity. Participants who returned a completed survey were eligible to receive an online gift card to Amazon.ca (an online retailer of books and other products) for $\$ 5.00$ by email to thank them for their time.

\section{Results}

Eighty-one completed surveys were returned. Because none of the survey questions were mandatory there are less than 81 total responses for many questions.

\subsection{Demographic Information}

Gender. The majority of respondents (65\%, or $77.38 \%$ ) reported their gender as female while a smaller proportion (15\%, or $17.86 \%)$ reported male.

Age. Average age of respondents was 38.11, with the youngest age given as 22 and the oldest as 63 . The standard deviation of age was 10.66, which assuming a normal distribution places $68 \%$ of respondents' ages between 27.45 and 48.77 .

Education level. Twenty-five respondents (29.76\%) had a certificate, some college/university or a college degree, while the majority (48 respondents, or $57.15 \%$ ) had a Bachelor's or Master's Degree.

The majority of workers indicated they have some post-secondary experience, suggesting either social service workers as a whole typically acquire a post-secondary education (possibly as a prerequisite for their work), or that social service workers with an experience of post-secondary education are more likely to participate in research.

Additionally the education level of respondents suggests that the majority of workers chose social services for 
their career rather than acquiring the job out of necessity (assuming that the education reported is focused on the social services).

\subsection{Work Experience}

Length of employment. Fifty (59.52\%) workers had been a social service worker for 6 years, or longer indicating that the survey results are drawn more from experienced workers than those new to the field. This also suggests that social service work is a career choice rather than a temporary job option for most of the respondents.

Current employment. Seventy-five respondents (89.29\%) were currently social service workers. This could mean that social service workers have a proactive rather than retroactive interest in improving their field, and are hopeful for improvement. Given that the stated goals of the study are to contribute to better working environments for social service workers, the large proportion of current workers who participated could mean that workers do not wait to realize that social service work is creating stress in their lives only after they leave or burn out—current workers appear aware that the working environment is untenable and are interested in improving it rather than simply moving on to other jobs.

When asked why they had left social service work (some respondents may have left the field and then returned-however there was no way of knowing if this took place) 10 respondents (11.90\%) said they had left to procure better pay and benefits or to advance their career, while 6 (7.14\%) said they had left because of burnout or emotional stress. Only 3 respondents (3.57\%) said they had left to attend college or university. This latter option might not constitute a permanent exit from the field, as the education the workers receive might be related to social service work and allow them to return to the field.

The relatively small proportion of people who said they had left social service work because of burnout or emotional stress could indicate that the respondents reached (most of whom were currently working as social service workers) did not proportionally represent those who had left the field due to burnout (and who might not keep in touch with online forums/research efforts in social services). Another option is that workers may have more than one reason for leaving social services, or might hesitate to name burnout/emotional stress as their sole or primary reason for leaving due to the low social desirability of admitting emotional distress.

Continued employment. Thirty-seven (44.05\%) respondents said that they planned to work 6 or more years as a social service worker, but a relatively large number of respondents (27\%, or $32.14 \%)$ also said that they were not sure how long they would continue.

The $44.05 \%$ who indicated they wanted to continue working 6 years or more suggests that social service work is seen as a long-term job option by many workers; this could also mean that the workers who chose that option enjoyed the work that they were doing, prompting them to plan on staying in the field. However, the proportion of respondents (32.14\%) who said they were unsure of their plans suggests that the balance of benefits vs. costs associated with social service work may not be clearly defined for workers, if they cannot give a definitive answer on whether they will remain in or leave the field.

Role expectations. When asked if they felt they were expected to present a composed, professional exterior in their job no matter how emotionally stressful the circumstance are, the vast majority of respondents (85.72\%) said that they felt that most or all of the time they were expected to present a composed, professional exterior in their job no matter how emotionally stressful the circumstances were. This suggests that there is pressure from the "professional" side of social service work for workers to conceal or repress the effects of emotional labour. This also suggests that informal attitudes or behaviour with clients might be seen by workers as at odds with the expectations of "composed" professionalism they perceive for themselves.

Job satisfaction. When asked if they felt there was more they could be doing for clients that their job description prevents them offering, many workers (29\%, or $35.80 \%$ ) answered in the affirmative, and gave reasons ranging from the lack of sufficient staffing or allowable overtime to the decentralized nature of services which could result in clients' needs going unmet due to gaps in service provision.

A common theme in answers was flexibility; clients needed a bit more or less time, or their needs ran overtime and workers were unable to meet their needs while staying within their scheduled hours. This suggests that giving workers more control over their time, more colleagues to share the load or simply more paid time to allocate could help workers to improve their services.

Eleven respondents (13.58\%) did not find their job description constraining, but their written answers such as "I always find a way to meet my clients’ needs” suggested that it was the flexible way in which they interpreted their 
job, rather than the official job description, which caused this feeling. Thirteen respondents (16.05\%) gave a written answer that named factors outside of their job description which affected them doing more for their clients (which was not categorized as either a positive or negative response); most of these responses indicated that while they were prevented from meeting their clients' needs in some ways, it was not specifically because of their job description. Some of these answers indicated that it was the social services system overall which frustrated their efforts to be effective, or that their agency simply did not have the time or money to serve everyone properly.

Forming an emotional relationship with clients. Of the 81 respondents, a majority of 68 (80.96\%) felt that emotional relationships were either expected of them or essential to their job. This suggests that emotional labour is an accepted part of social service work, as well as being an open part of employer expectations. Consistent with this, the majority (75 people, or $89.29 \%$ ) of workers also believed that these relationships are part of being a good social service relationships with clients, they would probably be aware both that it was considered by their employer to be an important part of their job, and that the relationships were ideologically aligned with the idea of a "good" social service worker.

Extra work hours. More than half of respondents (48\%, or 57.14\%) indicated that they worked unpaid hours at least occasionally, but close to a quarter $(19 \%$, or $22.61 \%)$ said that half the time or more they worked unpaid hours. As a representation of the greater population of social service workers, $22.61 \%$ is a large amount of people to be spending unpaid hours at their job on a regular basis. This is consistent with earlier research about the field that tied burnout and high turnover to higher work levels for social service workers in general [6]. These hours could also be linked to the aforementioned emotional labour that social service workers perform, as emotional labour could be more difficult to confine to specific hours of work.

In addition, the majority of respondents (44\%, or 52.38\%) said it was normal for workers to occasionally spend unpaid hours at work, and a similar $30.86 \%$ thought it was normal for workers to work unpaid hours anywhere from half the time to always. Roughly a quarter of respondents (24\%, or $28.57 \%)$ thought their employers were okay with them occasionally working these unpaid hours, and the same number (24\%, or $28.57 \%)$ said their employers approved of it most of the time or always.

In light of the responses workers gave for not being able to meet all of their clients' needs (needing more hours, more flexibility of more workers) the unpaid hours that many workers and employers seem to accept as part of the job could stem from a simple necessity. That is, that there is more work to be done than can be accomplished within the regular working hours. This is supported by more than a quarter of respondents (26\%, or 30.95\%) who indicated their reason for working overtime was because there was not enough hours in the workday to complete all of the work a standard client deserved. Similarly there is support for workers needing ongoing schedule flexibility in the proportion of respondents $(20 \%$, or $23.81 \%)$ who said that they worked extra hours to accommodate clients whose emotional needs could not be put off to a later time (just because work hours had ended).

Eighty of the 81 respondents also provided information about whether their employers approved of social service workers spending time on work outside of their regular hours. 17 (20.24\%) said that their employer never approved of this, while 24 (28.57\%) said that their employer approved of working past work hours occasionally and another 24 (28.57\%) said that their employers approved of it most of the time or always.

The majority of respondents (54\%, or $64.29 \%$ ) did indicate that they felt they did not have to engage with clients once they had left work, but they did feel that they had to assume their professional persona if approached by a client in the community. Given that social service workers (especially those in rural or remote areas) might live among relatively small or close-knit communities, this expectation could potentially be an extra source of stress as a worker might feel that they had to be "on" as a professional all the time.

Leaving work at work. Most respondents (56\%, or 66.67\%) did not think it was possible to completely disengage from their work environment, though a similarly high proportion (54\%, or 64.29\%) said that most of the time or always they were expected to "leave work at work". The written answers for why or why not respondents believed they were asked to "leave work at work" followed a theme. Strong consideration was given by many respondents to the fact that workers' personal time and mental health needed space away from work issues to allow for self-care; however, given the proportion of workers who answered that they believe this to be impossible, this expectation may only impose more stress on workers by emphasizing the positive mental health effects of something they feel unable to do.

Thirty-one respondents (36.90\%) reported at least occasionally reflecting on clients and their issues after leaving the workplace, while 49 (60.49\%) reflected on clients and their issues after work anywhere from half the time to always. This supports the idea that workers may be unable to disengage from their workplace effectively, 
despite being strongly aware that "leaving work at work" would be better for their mental health. Given that the majority of workers also believe that having emotional relationships with clients is an important part of their job, emotional labour and/or attachment could be a contributing factor in the inability to disengage from social service work as opposed to other forms of employment that do not include emotional relationships.

However, when asked if reflecting on clients and their issues after hours had a negative effect on their life outside of work, almost half (38\%, or 45.24\%) thought that it did not have a significant effect on their life outside of work, while 28 respondents (33.33\%) thought that it did affect them negatively. Given that most respondents had been in social service work for 6 years or more, this could indicate that after a certain period of time in the field workers might become accustomed to the balance of emotional labour and the day to day expectations of their profession, and experience less negative effects. It could also indicate that after working in the field a while workers might become accustomed to carrying emotional labour and reflecting on clients outside of work, and may not notice the effect it has (if any) on their lives outside of work.

\subsection{Statistical Testing}

The goal of this study was to investigate the relationship among variables such as age/gender/length of employment and the perceptions of emotional labour, professional expectations and mental health supports held by workers. Variables were cross-tabulated and any variables that met the criteria were tested using a Chi-square test for independence. As shown in the literature review, previous studies indicate that there are trends, which may be expected within the social service worker population. I performed Chi-Square testing on all of the nominal data to compare the actual data (at a 0.05 significance level) against the results expected if the data were unrelated to each other.

Not all of the variables met the criteria for Chi-square testing, which are that no more than $20 \%$ of the expected cell frequencies be less than 5 , and that the variables be assumed to be independent of each other. In this case, since the variables represent data collected from individuals all over B.C. they can be safely assumed to be independent of each other, and the tests that were excluded were those that did not meet the former criteria.

Age and continued reflection. A Chi-square test on the effects of social service workers' age on their continued reflection of work issues after they had left work showed that age and continued reflection are independent, that is, that a worker's tendency to continue reflecting on work after leaving work does not depend on their age. $\mathrm{X}^{2}$ $(4, N=79)=4.28, p=0.369$. However, given that the average age of the workers in the study was 38 and this suggest most workers who participated were old enough to have significant work experience, this suggests that a larger test might show a correlation between age and continued reflection based on the probable correlation between age and experience and the likelihood that experienced workers reflect outside of work hours.

Age and overtime reasons. A Chi-square test on the effects of social service workers' age on their reasons for staying overtime at work showed that age and overtime reasons are not independent; a worker's reasons for working overtime were dependent on their age, $\mathrm{X}^{2}(4, N=75)=128.01, p=0.000$. The distribution of answers (Table 2) suggests that younger workers (20 - 30 yrs.) work their overtime hours only when a client is immediately in a state of need, either because of distress that could happen at the end of the work day and not be put off, or because they have met a client out in the community and need to address their needs at that time.

However, workers 30 - 40 years old, who may have more experience in the field, primarily say that they work later because there are not enough hours in the workday to complete all of their work to the standard deserved by their clients. While the option chosen by younger workers (clients' immediate needs) may fall under this category, it is significant that the slightly older workers chose to describe their overtime work as the result of not having enough work hours.

Table 2. Responses by respondent age to survey Question 18. "If you do work extra (unpaid) hours, what are your reasons for doing this extra work?”

\begin{tabular}{|ccccc}
\hline Respondent age & $\begin{array}{c}\text { Client distress can't } \\
\text { be put off/ presents in community }\end{array}$ & $\begin{array}{c}\text { Not enough } \\
\text { hours in workday }\end{array}$ & $\begin{array}{c}\text { Strengthening } \\
\text { relationships/other }\end{array}$ & $\begin{array}{c}\text { Total \# of } \\
\text { responses }\end{array}$ \\
\hline 20 - 30 yrs. & 25 & 0 & 0 & 25 \\
$31-40$ yrs. & 2 & 24 & 0 & 26 \\
$41+$ & 0 & 2 & 22 & 24 \\
\hline
\end{tabular}


This suggests two things: first, experienced workers believe they are doing unpaid overtime work that could be done within paid hours if more hours or workers were available. Second, that workers do a variety of work that could be anything from client meetings to paperwork after hours, not because there were needs present that could not be shifted to the next work day but simply because there was no other time to complete that work.

Finally, workers who were over the age of 41 primarily chose the option of strengthening relationships with clients or "other" (responses ranged from client needs to volunteering with certain programs). If these workers have been in social service work for a significant length of time, it could mean that more experienced workers value the relationships they have with clients and consider them a necessary part of their job, something worth investing unpaid hours in. This may also suggest that older workers regardless of experience find that relationships with clients are important but more tangible tasks like paperwork take precedent in work hours, so workers have found it necessary to spend time on these relationships during unpaid hours.

Age and leaving work at work. Chi-square testing on the effects of social service workers' age on their belief that it is possible to "leave work at work" showed that these factors are independent of each other, that is that age has no effect on whether a worker believes it is possible to "leave work at work". However, it is worth noting that the test was very close to significant, lower than the cutoff score for the Chi square test (5.992) that would have indicated a positive result by just 0.09 as $\mathrm{X}^{2}(2, N=79)=5.90, p=0.052$ (see Table 3).

Continued reflection and the effects on life outside of work. Chi-square testing on the effects of workers reflecting on work outside of work hours on whether workers believed that type of reflection had a negative impact on their life outside of work showed that these factors were not independent; the frequency with which a worker reflected on work after work hours was dependent on whether they believed reflection had a negative impact on their life (Table 4). $\mathrm{X}^{2}(4, N=81)=11.88, p=0.018$.

The dependent relationship indicated that workers who said they reflected a lot (most of the time, or always) believed that the time spent in reflection did negatively impact their life outside work, while correspondingly people who spent less time reflecting said that the negative effects of reflecting were not significantly affecting life outside of work. While this relationship may just logically show the fact that the more you reflect about work the more negatively it affects your life, it also indicates that unless the reflection happens more than half the time workers do not consider it to have any significantly negative effects. This suggest that advising workers to "leave work at work" may not be a useful or necessary act since any workers for whom reflection does not take up more than half of their non-work hours there are no significant negative effects. As discussed in the literature review, instructing workers to "leave work at work" is both ineffective (since most workers reported they still thought about work after work hours) and possibly harmful because it could create cognitive dissonance in workers as they struggle to disengage.

Table 3. Responses by respondent age to survey Question 19. "Do you believe that it is possible for you to "leave work at work".

\begin{tabular}{cccc}
\hline Respondent Age & Yes & No & Total \# of responses \\
\hline $20-30$ yrs. & 3 & 21 & 24 \\
$31-40$ yrs. & 10 & 16 & 26 \\
$41+$ & 12 & 17 & 29 \\
\hline
\end{tabular}

Table 4. Responses (organized by rating of negative effects of reflection) to Survey Question 12. "Do you continue to reflect on clients and their issues after you have left work, or on days off?”

\begin{tabular}{|cccc}
\hline \multicolumn{4}{c|}{ Continued reflection on clients after work or on days off } \\
\hline Negative effect on life outside work* & Never/occasionally & About half the time & Most of the time/always \\
\hline Yes & 8 & 4 & 16 \\
No & 8 & 5 & 2 \\
\hline Not significantly & 16 & 13 & 9
\end{tabular}

\footnotetext{
${ }^{*}$ As measured by response to question 13 "If you reflect on clients while you are not at work, do you think this has a negative effect on your life out-
} side of work?” 


\subsection{Limitations}

The scope of this study is limited in a number of ways. Firstly, the research design, to allow for anonymity, randomized all responses to the survey so that only grouped responses could be reported. This prevented any correlation within individual surveys between respondents' answers. This study examines a specific population of BC social service workers, individuals in British Columbia who are employed in a position where they provide support for individual clients' mental, emotional and social welfare over an extended period of time. There are conditions that affect the experiences of this population that may not affect social service workers in other areas of Canada or social service workers outside of Canada. An example of this is policies that dictate professional standards for social service worker within BC, which may be drastically different from the expectations of this kind of work in other parts of the world. For this reason, results of this research cannot be generalized to make statements about all social service workers, or social service work as a whole. Therefore, any use of the results of this study must consider its scope and context.

Secondly, the survey was available online, and this may have unintentionally excluded some workers who do not have computer access. Additionally, the survey was promoted through a number of online email lists and Facebook groups, whose membership might exclude certain people who are less engaged online. Participants in the study are self-selected (from within the population of social service workers in British Columbia) as they have chosen to participate in this study. This presents an opportunity for bias if the willingness to participate in research is influenced by a secondary factor, such as a familiarity with research.

Thirdly, the study was limited in the questions that could be asked about resources that employers offer to support workers' mental or emotional health were limited to because that might have affected the willingness of the various organizations to pass on the survey to their workers.

The survey used to collect information from participants is intended to measure distinct factors such as subjective professional expectations, emotional labour experiences and perceived available supports. The survey appears to have face validity as it was examined by the researcher and her thesis supervisor. Despite these efforts it is always possible that the answers given on the survey do not reflect the factor they are intended to measure. Social research is complex because definitions and measurements used vary [9] and it is important that any results of the survey acknowledge this context.

Many of the questions used are subjective, meaning that the information given by respondents could be skewed by variations in memory abilities or the different criteria specific respondents might use to answer questions. For example, one respondent could consider the ability to "leave work at work" as not being continuously engaged with workplace thoughts after leaving, whereas another respondent could consider "leave work at work" as not being even intermittently engaged with thoughts of work after leaving. However, because the survey specifically examines the subjective viewpoint of social service workers this does not affect the validity of the data unless the results are taken out of context and considered erroneously to reflect objective measures.

\section{Conclusions}

The results of the survey showed an experienced, dedicated group of workers in a profession many people appear to take up specifically to build relationships and create positive change. Additionally, the answers given showed that the majority of respondents are proactively trying to improve their field and would like to continue working in it, despite an awareness of the prevalent issues of emotional exhaustion and burnout they experience and share with the broader field of social service work [6].

The analysis of age suggests that most workers do devote their professional lives to social service work specifically, as most surveyed had been in the field for 6 or more years, the maximum category given. The preference for continuing in social service work despite a number of workers finding themselves working unpaid overtime and dealing with intrusive emotional labour outside of work suggests that consistent with previous analyses of the field, social service work is not merely a job to those who do it, but has a vocational aspect and is consistent with empathetic and caring world views [1] [10]. This is supported by the relationship between age and the reasons workers gave for taking on paid overtime; the younger workers were, the more likely they were to take on unpaid overtime because it was unavoidable or a situation arose it was inconvenient to defer. Older workers, however, consistently engaged in overtime to build relationships and to bring the level of service they provided to the standards deserved by clients. The positive relationship between empathy and burnout in available social service work literature [2] [6] [11] suggests that empathetic workers may burn out sooner or suffer from more emotional 
distress during their social service work career. However, the positive correlation between age and a focus on relationship building at the workers' own cost (unpaid overtime) suggests a number of different ideas that workers may have about prioritizing their job, and their own emotional health.

Firstly, it is possible that building relationships is crucial enough to their job that workers are willing to prioritize it even as it costs their own emotional health. This would explain both the high rates of burnout in the field and the prioritization workers gave to relationships in the study, where the majority indicated it was an important or essential part of their job. Such a belief could lead workers to continue prioritizing workers even as they have seen their colleagues burn out and perhaps leave the field. It also suggests that even workers who are not in a state of burnout presently are investing a significant amount of their own time and emotional energies into client relationships and thus are putting their mental health at risk [6] because they believe effectively doing their job requires it. This is also supported by the correlation between age of workers and prioritizing client relationships; if workers limited their empathetic relationships with clients because they saw others burning out or realized they were burning out themselves, the correlation between the two variables would be expected to go in the other direction with older workers prioritizing relationships less and their own mental health more. Instead, it seems that whatever the risks, relationships and properly serving clients needs (even outside paid hours) becomes more important as workers become older and more experienced.

Secondly, the consistent prioritization of overtime for ongoing tasks (client relationships and meeting job standards) suggests that workers are aware that their job asks more of them than they are paid for, and in order to successfully serve their clients they must take up the slack. If workers only ever did as much as they are able (and paid for), except for emergencies, the correlation in the data would again be expected reversed—older workers would be expected to put in unpaid hours for emergencies only, and the young workers might be expected to work overtime consistently to try to meet the standards of care which are impossible to meet in the given hours. The actual correlation, however, suggests that older more experienced workers both know that they will never be able to do their job in the hours they are given, and believe that doing their job effectively long-term is more important than preserving their non-work time for exclusively non-work uses.

Finally, the correlation between age and leaving work at work, though not significant, came very close to significance and may have shown significance in a larger study. As workers participating in the study had an average age of 38 and the majority had worked $6+$ years in social service work, it is possible to say that experienced workers made up the majority of the study. And the majority of these experienced workers did not believe it was possible to "leave work at work" though a similar majority said that their employers thought they should. This means that experienced workers have not found a way to disengage from the emotional demands of their job, nor might they feel comfortable seeking support or approval for their unpaid investment of hours as they know that their employers believe they should be able to "leave work" behind both physically or mentally if they want to.

Combined with the large number of workers who find the reflection on work in non-work hours intrusive, holding these conflicting beliefs simultaneously suggests that though experienced, mature workers are not unaware of the expectations of their employers to "leave work at work" the majority likely believes that to perform the job to the ideological standards they believe in [2] they must take extra hours, emotional stress [12], and intrusive thoughts upon themselves. Workers have essentially been told to perform at a level that is untenable with their paid hours, told they must not put in more hours, and are prompted by their own ideologies to do the best job they can anyway by investing emotionally in the job until they burn out. An unsustainable system sustained only by consistent turnover, with apparently little thought to the emotionally exhausted workers churned out year after year who may have to leave the job they believe in, because it uses them up.

\section{Acknowledgements}

This research was strongly supported by the guidance, insight and expertise of Dr. Paul Madak and I would like to thank him for all of the "invisible hours" which he contributed.

\section{References}

[1] Henderson, J. and Forbat, L. (2002) Relationship-Based Social Policy: Personal and Policy Constructions of “Care”. Critical Social Policy, 22, 669-687. http://dx.doi.org/10.1177/02610183020220040601

[2] Kosny, A. and MacEachen, E. (2010) Gendered, Invisible Work in Non-Profit Social Service Organizations: Implications for Worker Health and Safety. Gender, Work \& Organization, 17, 359-380. 
[3] Gregor, C. (2010) Unconscious Aspects of Statutory Mental Health Social Work: Emotional Labour and the Approved Mental Health Professional. Journal of Social Work Practice, 24, 429-443. http://dx.doi.org/10.1080/02650531003791012

[4] Gorman, H. (2000) Winning Hearts and Minds? Emotional Labour and Learning for Care Management Work. Journal of Social Work Practice, 14, 149-158. http://dx.doi.org/10.1080/02650530020020546

[5] Dybicz, P. (2012) The Ethic of Care: Recapturing Social Work’s First Voice. Social Work, 57, 271-280. http://dx.doi.org/10.1093/sw/sws007

[6] Barford, S.W. and Whelton, W.J. (2010) Understanding Burnout in Child and Youth Care Workers. Child \& Youth Care Forum, 39, 271-287. http://dx.doi.org/10.1007/s10566-010-9104-8

[7] Rupert, P.A. and Morgan, D.J. (2005) Work Setting and Burnout among Professional Psychologists. Professional Psychology, Research and Practice, 36, 544-550. http://dx.doi.org/10.1037/0735-7028.36.5.544

[8] Ingram, R. (2013) Emotions, Social Work Practice and Supervision: An Uneasy Alliance? Journal of Social Work Practice, 27, 5-19. http://dx.doi.org/10.1080/02650533.2012.745842

[9] Loseke, D.R. (2013) Methodological Thinking: Basic Principles of Social Research Design. Sage Publication, Inc., Thousand Oaks.

[10] Gerdes, K.E. and Segal, E. (2011) Importance of Empathy for Social Work Practice: Integrating New Science. Social Work, 56, 141-148. http://dx.doi.org/10.1093/sw/56.2.141

[11] Pottage, D. and Huxley, P. (1996) Stress and Mental Health Social Work: A Developmental Perspective. International Journal of Social Psychiatry, 42, 124-131. http://dx.doi.org/10.1177/002076409604200206

[12] Gerdes, K.E., Lietz, C.A. and Segal, E.A. (2011) Measuring Empathy in the 21st Century: Development of an Empathy Index Rooted in Social Cognitive Neuroscience and Social Justice. Social Work Research, 35, 83-93. http://dx.doi.org/10.1093/swr/35.2.83 


\section{Appendix A.}

\section{A.1. Description of the Research, and Requirements for Participation and Consent}

I am a Graduate student in Gender Studies, at the University of Northern British Columbia (UNBC) and I am doing survey research as part of the credits for my degree. In the past I have been employed as a group home worker at Eagle Nest Community And Aboriginal Services (ENCAAS) in Prince George, which was my introduction to the social services field. Though it is important to disclose this as part of my background, this research project stems from my position as a student researcher, and does not represent any interest or contribution of ENCAAS.

Social service workers are defined, for the purpose of this study, as individuals who are employed in a position where they provide support for individual clients' mental, emotional and social welfare over an extended period of time. (This definition intentionally excludes occupations such that offer primarily medical care such as nursing or hospice work, because caring for sick, injured or dying individuals exposes workers to emotional and mental stressors that are outside the scope of the study).

You qualify for this study if you are currently, or have been, employed as a social service worker. This study is designed to examine your experiences as a social service worker and how your employment may affect your life outside of work. Specifically, this study examines the interaction of emotional labour and professional expectations with the ideological stance of workers and their ability to effectively cope with their job expectations. The purpose of the study is to assess whether current expectations of social service workers are consistent with the support and personal benefits they are given.

In the results of the research, only grouped data will be reported. The responses from everyone who answers the questionnaire will be combined and no individual responses will be identified, meaning that in any written work resulting from the study, no one will know what you have said, or be able to match a pattern of responses to you. Individual companies are not noted on the questionnaire and so they will not be visible in any outcomes. The survey does not ask for any information about your location, identity or the agencies you have worked for now or in the past.

Question 4 asks the first 3 digits of your postal code-the purpose of this question is to allow for data to be compared by rural and urban areas; these 3 digits are not enough to identify a specific location, and will not be used for any purpose other than broad comparisons of urban and rural areas.

Your responses to this questionnaire are considered confidential, and will be kept as secure as the researcher can make them. There are two options for completing the survey: on the secure UNBC survey research platform, or the UNBC SONA Psychology Research Participation System (this option is only available to current graduate or undergraduate students at UNBC). Digital copies of survey data will be kept on a secure hard drive to which only the researcher has access; any printed data will be kept in the locked office of Paul Madak at UNBC, in a locked container to which only the researcher has access.

After a period of 5 years, all of the data collected will be destroyed. Printed records will be shredded, and records stored on a computer hard drive will be erased using commercial software applications designed to remove all data from the storage device.

The only exception to the above conditions of confidentiality is responses that indicate criminal behaviour, which will be reported to the RCMP.

Do not place any identifying marks, such as your name, anywhere on the questionnaire. It will take between 12 - 15 minutes to complete the survey, and you are free to withdraw from it at any time. Participation in this study is completely voluntary, and you can skip any questions that you do not want to answer. You can complete the survey at anytime up until February $20^{\text {th }}, 2015$.

By submitting your completed survey, you are giving permission for your responses to be used for the research purposes outlined above. At any point before you submit your survey, you have the option of withdrawing your responses. If you have completed all or part of the survey but do not want your responses to be used for research purposes, you can exit the survey and none of your responses will be saved, or available for inclusion in the study.

The potential benefits of this study are the knowledge that your experiences are being taken into account in research on your area of employment, and that research could make recommendations to social service providers regarding any patterns that emerge in the results of the research, and those recommendations could improve the 
quality of the workplace. The risks are of feeling uncomfortable during the study and/or having an emotional response triggered by the content of the questionnaire.

If you feel in any way distressed during the completion of the questionnaire you can withdraw from the study and you will not be penalized in any way. You will also be able to withdraw your responses, as outlined above.

There is also a risk that participants might be identified in connection to the research. To prevent this there are the conditions of anonymity (not marking one's name, company or any other identifying factors) placed on the study, as well as the security under which the data is placed (outlined above) to do everything humanly possible to keep the study confidential.

If you would like to access support after completing this survey, counsellors can be found for most areas of BC by accessing the BC Association of Clinical Counsellors at www.bc-counsellors.org/. For local participants there is counselling available at the Community Care Centre downtown in Prince George at $13103^{\text {rd }}$ Avenue. The phone number for information or appointments is 250-960-6457.

Upon completion, the results of this study will be made available for organizations that participated in distribution of the study to display. If you have questions regarding this study, or would like to receive a copy of the results when the study is completed for your personal use or display in your organization, please contact the researcher using the following information:

Ley Fraser

Supervisor: Paul Madak

bfraser@unbc.ca

(250) 960-6520

If you have complaints about this study, please contact the UNBC Research Ethics Board:

UNBC-Office of Research

(250) 960-6735

3333 University Way

General E-mail: reb@unbc.ca

Prince George, BC V2N 4Z9

Canada

\section{A.2. Balancing Caring Relationships and Professional Standards in Social Service Work}

You can now begin the survey. All questions ask about your personal experience as a social service workers, which is defined as any position where you provided support for individual clients' mental, emotional and social welfare over an extended period of time.

Please give each question your full attention and consider all of the options before marking your answer. Circle the response that you have selected, or write in the space provided.

1 . What is your gender?
a) Male
b) Female
c) Other (please specify)

2. How old are you? years old

3. What is your education?
a) High school
b) Certificate
c) Some college
d) College degree
e) Some university
f) University degree
g) Masters degree
h) $\mathrm{PhD}$ degree

4. What are the first 3 digits of your postal code?

5. How many years have you worked, or used to work, in the social service field (as defined in the introduction to this survey)?

a) 1 year or less

b) 2 - 3 years 
c) 4 - 5 years

d) 5 years

e) 6 or more years

6. Are you currently working as a social service worker?

a) Yes

b) No

6a. If you are currently working as a social service worker, how long do you plan to continue?

a) 1 year or less

b) 2 - 3 years

c) 4 - 5 years

d) 6 or more years

e) Not sure

f) Not working any longer as a social service worker

6b. If you no longer work as a social service worker, why did you decide to change your profession?

a) To advance my career

b) To attend college/university

c) Because of burnout or emotional stress

d) To find better pay/benefits

e) Other

f) I am still employed as a social service worker

\section{Job Expectations as a Social Service Worker}

7. In your work, do you think you are expected to form a caring relationship with your clients? Circle the option that most closely matches your experience.

a) No, I am discouraged from forming any kind of connection with clients.

b) No, I am not asked to form this kind of relationship.

c) Forming a relationship with the client is neither encouraged nor discouraged.

d) Yes, I feel that creating this relationship is expected of me.

e) Yes, I feel creating this relationship is an essential part of my job.

8. Do you believe that creating a relationship where you truly care about clients and their well-being is part of being a good social service worker?
a) Never
b) Occasionally
c) About half of the time
d) Most of the time
e) Always

9. Do you ever work unpaid hours outside of your regular hours, in order to help your clients?

a) Never

b) Occasionally

c) About half of the time

d) Most of the time

e) Always

10. Do you think that it is normal for a social service worker to work outside of regular paid hours?
a) Never
b) Occasionally
c) About half of the time
d) Most of the time
e) Always

11. Does your employer approve of workers spending time on work outside of regular work hours?

a) Never

b) Occasionally

c) About half of the time

d) Most of the time

e) Always 
f) The employer does not know

12. Do you continue to reflect on clients and their issues after you have left work, or on days off?

a) Never

b) Occasionally

c) About half of the time

d) Most of the time

e) Always

13. If you reflect on clients while you are not at work, do you think this has a negative effect on your life outside of work?

a) Yes

b) No

c) Not significantly

14. Do you think that your employer expects you to engage with clients outside of your official work hours? Circle the option that most closely matches your experience.

a) No, once I leave work I have no further obligations

b) No, but I am still expected to maintain my professional role while in the community if clients speak to me.

c) Officially, once I leave work I am expected to separate from my professional role and not acknowledge those relationships

d) I am not sure, those expectations have not been made clear to me

15. Do you feel in your job you are expected to present a composed, professional exterior not matter how emotionally stressful the circumstance are?
a) Never
b) Occasionally
c) About half of the time
d) Most of the time
e) Always

16. Do you ever think that there is more you could be doing to help a client, which your job description prevents you from offering? Please explain your answer.

17. Do you feel guilty if you work unpaid hours outside of your regular work hours?
a) Never
b) Occasionally
c) About half of the time
d) Most of the time
e) Always

18. If you do work extra (unpaid) hours, what are your reasons for doing this extra work?

a) Clients experiencing emotional distress that cannot be put off to a later time

b) Meeting clients in the community who present needs at that time

c) Not enough hours in the workday to complete all work to the standard clients deserve

d) To spend time strengthening the relationship with a client

e) Other:

19. Do you believe that it is possible for you to "leave work at work", to completely disengage from your work environment and all its relationships when you are not at the workplace?
a) Yes
b) No

19a. In your job, do you think that you are expected to "leave work at work"?
a) Never
b) Occasionally 
c) About half of the time

d) Most of the time

e) Always

19b. Why or why not?

20. Do you know of any resources that your employer offers to support workers' mental or emotional health?

21. If you were able to add a program to your place of work to support workers' mental and emotional health, what would you choose?

22. Do you have any comments on the subject of this survey that you would like to share?

The End! (); Thank you for your participation. Your responses are of great value and importance to the research community. By pressing the "submit” button, you are giving your consent for your responses to be used for the research purposes outlined in the in the Description of the Research and Requirements for Participation and Consent on the first pages of the survey. If you are unsure, please go back to review that section now. If you consent, press the "submit" button to submit your responses.

If you would like to receive a \$5.00 Amazon.com gift card as a token of appreciation for your participation, please enter an email address below and I will email you the code for your gift card. 